Supporting Information

\title{
General Strategy for Integrated Bioorthogonal Prodrugs: Pt(II)- Triggered Depropargylation Enable Controllable Drug Activation In Vivo
}

Tao Sun, ${ }^{\#}$ Tian Lv, ${ }^{\#}$ Jianbing Wu, ${ }^{\#}$ Mingchao Zhu, Fei Yue, Jie Zhu, Yihua Zhang and Zhangjian Huang*

State Key Laboratory of Natural Medicines, Jiangsu Key Laboratory of Drug Discovery for Metabolic Diseases, Jiangsu Key Laboratory of Drug Screening, China Pharmaceutical University, Nanjing 210009, P. R. China

\#These authors contributed equally to this work.

Table of Contents

1. Supplementary figures and table S2-S9

2. ${ }^{1} \mathrm{H}$ NMR, ${ }^{13} \mathrm{C}$ NMR, HRMS and HPLC spectra for compounds 14-17 S10-S17 


\section{Supplementary figures and table.}<smiles>NP(N)(Cl)(Cl)Br</smiles>

1<smiles>N[PH]1(N)OC(=O)C2(CCC2)C(=O)O1</smiles>

2
Pt(IV):<smiles>Cc1cccc(P(C)(C)(C)C)c1</smiles>

3

4

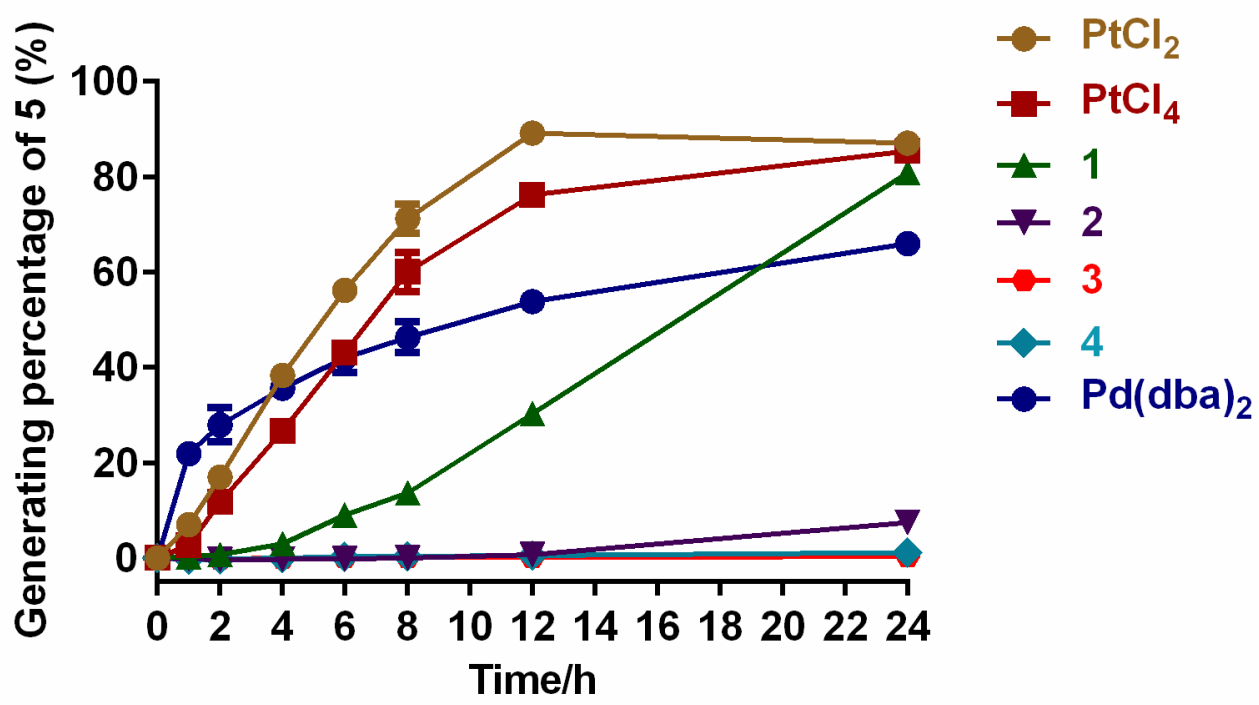

Figure S1. Compound 5a $(250 \mu \mathrm{M})$ was reacted with platinum compounds or $\operatorname{Pd}(\mathrm{dba})_{2}(250 \mu \mathrm{M})$ in $\mathrm{PBS}$ $(5 \mathrm{~mL}, \mathrm{pH} 7.4)$ containing $5 \% \mathrm{DMSO}$ at $37^{\circ} \mathrm{C}$. Aliquots $(300 \mu \mathrm{L})$ at each time point $(0,1,2,4,6,8,12$, $24 \mathrm{~h}$ ) were subjected to 96 -well plates and measured the fluorscence intensity ( $\lambda_{\mathrm{ex} / \mathrm{em}}=325 / 455 \mathrm{~nm}$ ) to determine the concentrations of highly fluorescent compound $\mathbf{5}$ according to the previously established standard curve of concentrations-fluorenscence intensity. Data were expressed as the mean \pm SD from three experiments. 

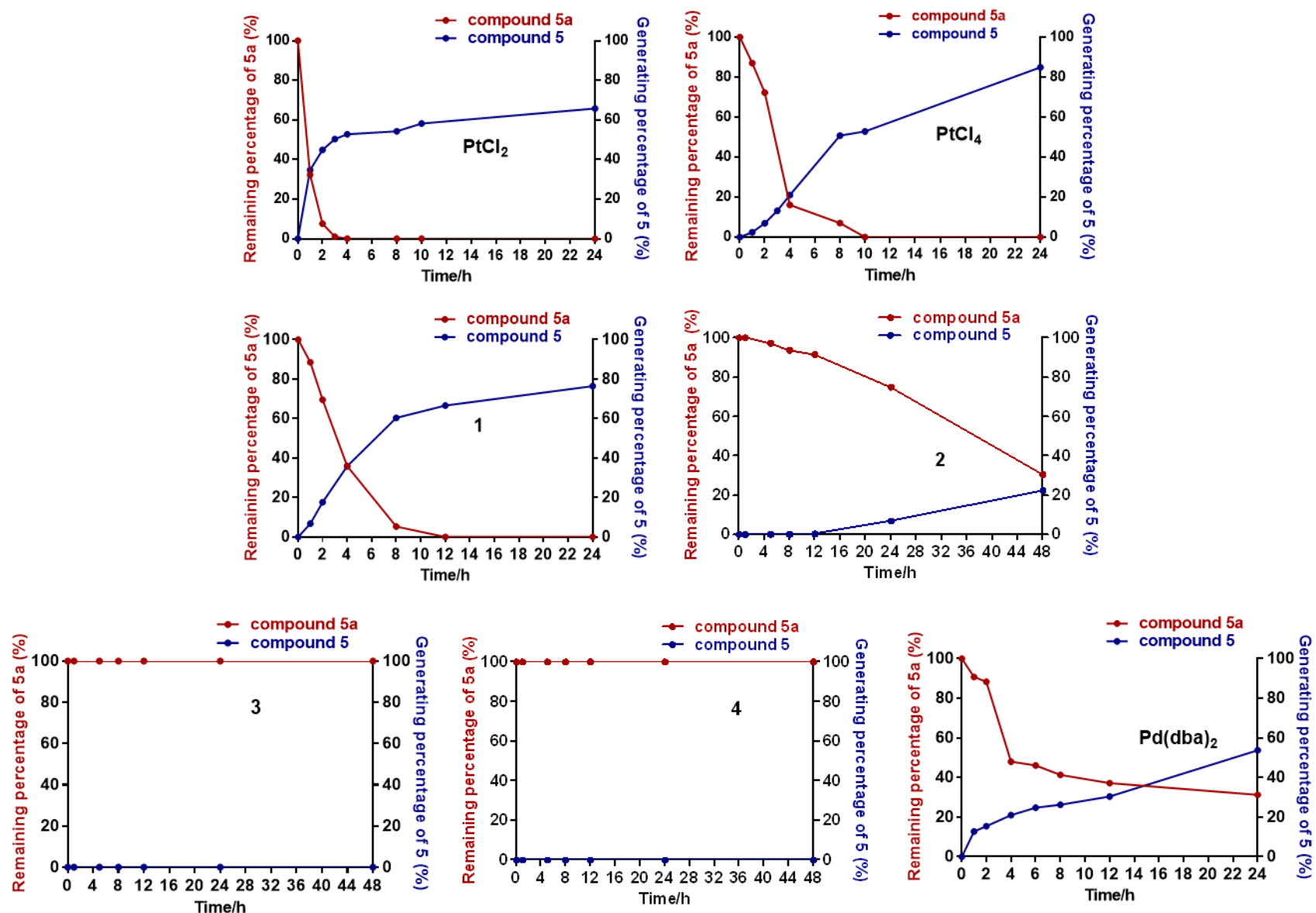

Figure S2. Compound 5a $(500 \mu \mathrm{M})$ was reacted with platinum compounds or $\mathrm{Pd}(\mathrm{dba})_{2}(500 \mu \mathrm{M})$ in $\mathrm{PBS}$ $(5 \mathrm{~mL}, \mathrm{pH} 7.4)$ containing $5 \% \mathrm{DMSO}$ at $37^{\circ} \mathrm{C}$. Aliquots $(600 \mu \mathrm{L})$ at each time point $(0,1,2,4,8,12,24$, or $48 \mathrm{~h}$ ) were subjected to HPLC analysis to determine the concentrations of remaining 5a and the concentrations of generating $\mathbf{5}$ according to the previously established standard curve for each compound. 

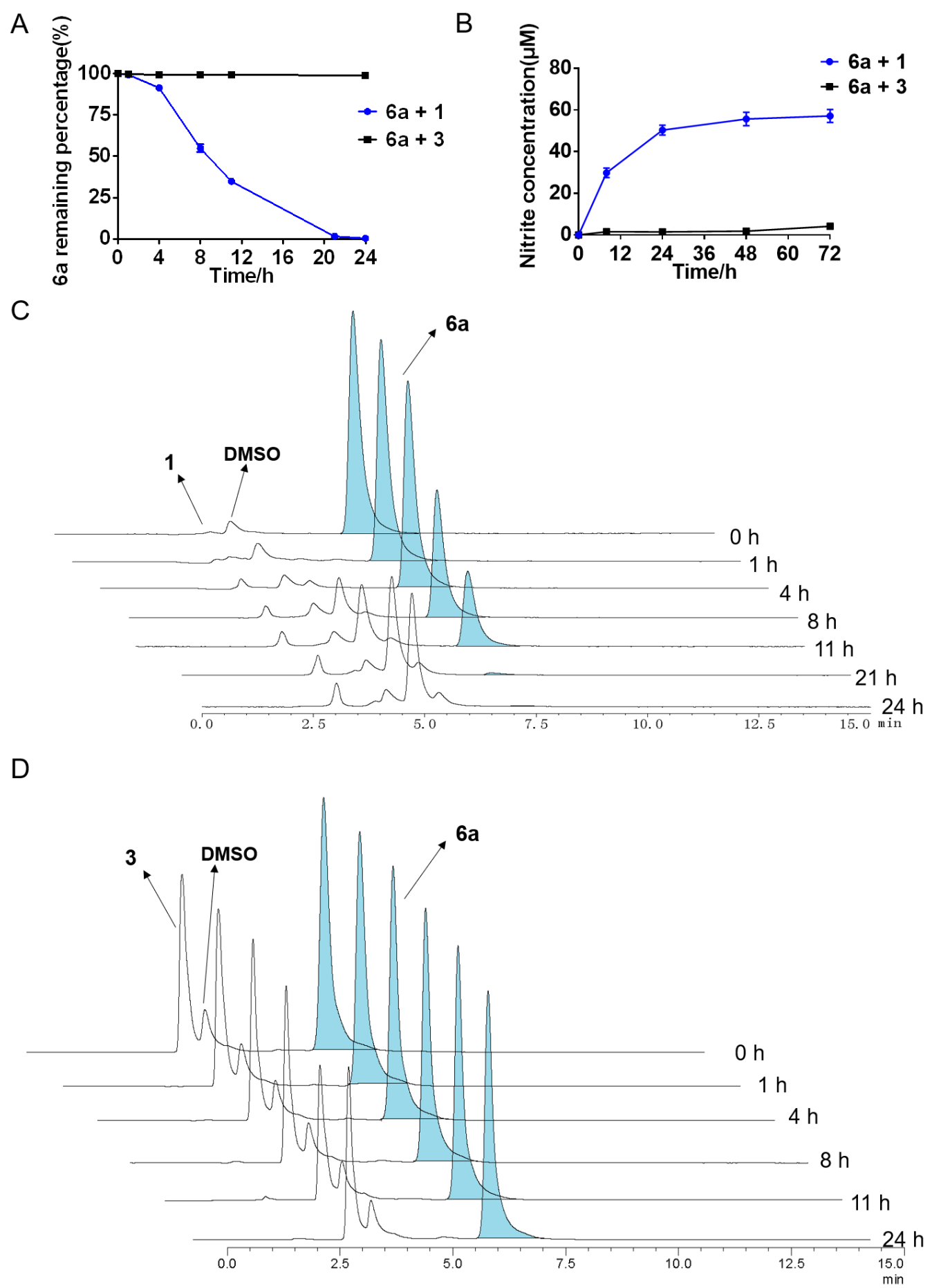

Figure S3. The A) degradation of compound $6 \mathbf{a}(500 \mu \mathrm{M})$ and B) NO release from $6 \mathbf{a}(125 \mu \mathrm{M})$ in the presence of equivalent concentrations of 1 or 3 in PBS buffer $\left(\mathrm{pH} 7.4,37^{\circ} \mathrm{C}\right.$, DMSO/PBS = 5/95, v/v). Aliquots $(600 \mu \mathrm{L})$ at each time point were subjected to HPLC analysis to determine the concentrations of remaining concentrations of $6 \mathbf{a}$. Aliquots $(400 \mu \mathrm{L})$ at each time point were analyzed by Griess reagent to determine the concentreations of nitrite $\left(\mathrm{NO}_{2}^{-}\right)$. Error bars represent $\pm \mathrm{SD}$ from three independent experiments. HPLC analysis $(\lambda=254 \mathrm{~nm})$ of the reaction mixture of compound $\mathbf{6 a}(125 \mu \mathrm{M})$ with $\mathbf{C}) \mathbf{1}$ $(125 \mu \mathrm{M})$ or D) $3(125 \mu \mathrm{M})$ in PBS solution containing $5 \%$ DMSO $\left(\mathrm{pH}=7.4,37^{\circ} \mathrm{C}\right)$ at each time point. 
Table S1. Yields of 1-mediated cleavage reactions. ${ }^{a}$
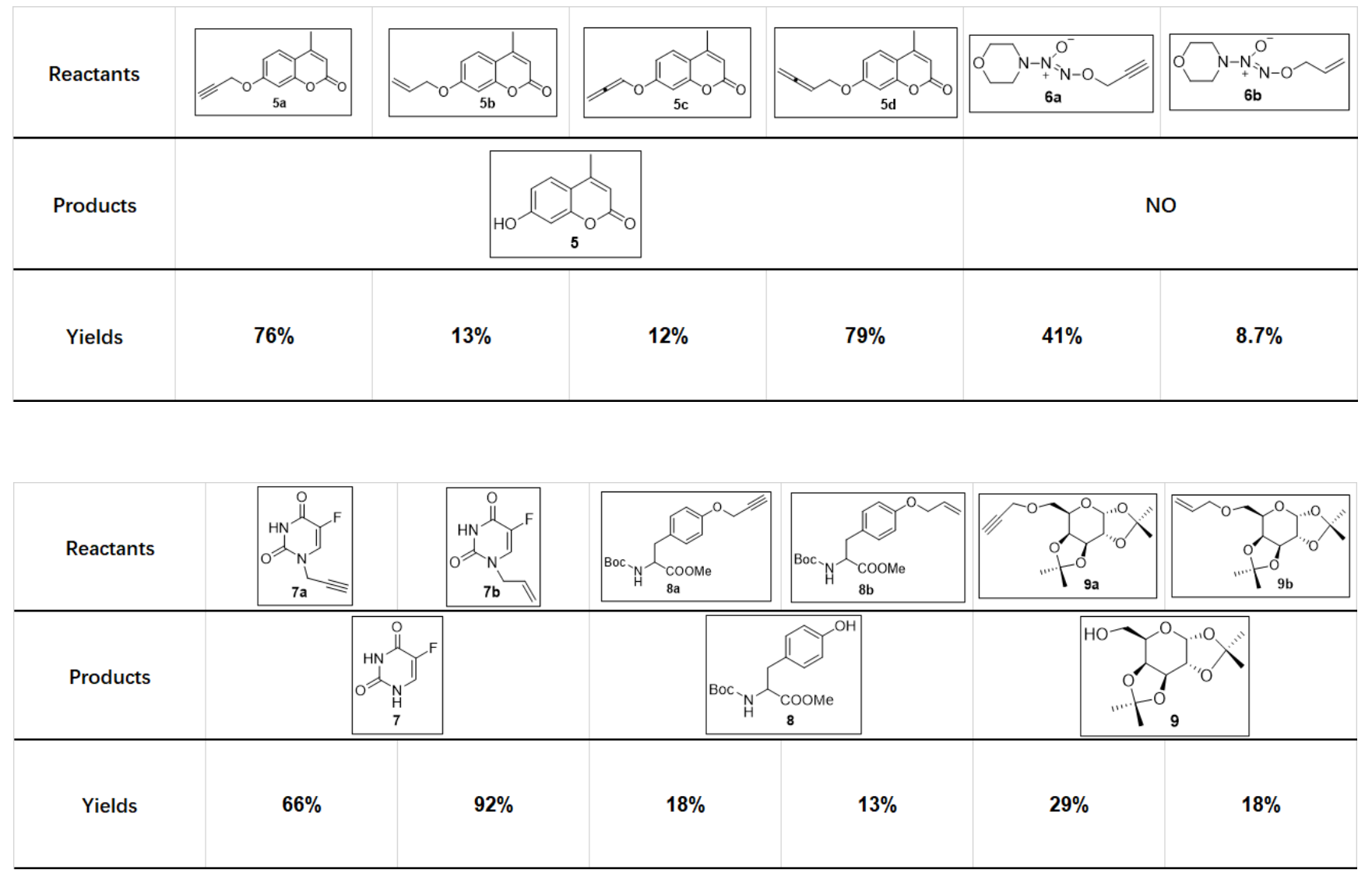

${ }^{a}$ 1-mediated cleavage reactions of one equivalent substrate were performed in PBS (pH 7.4) containing $5 \%$ DMSO at $37^{\circ} \mathrm{C}$ for $24 \mathrm{~h}$. As described in the Experimental Procedures section, the reaction solution was subjected to HPLC to determine concentrations of products. In the cases of $\mathbf{9 a}$ and $\mathbf{9 b}$, the reaction mixture was subjected to flash chromatography to get the isolated yields of 9 .
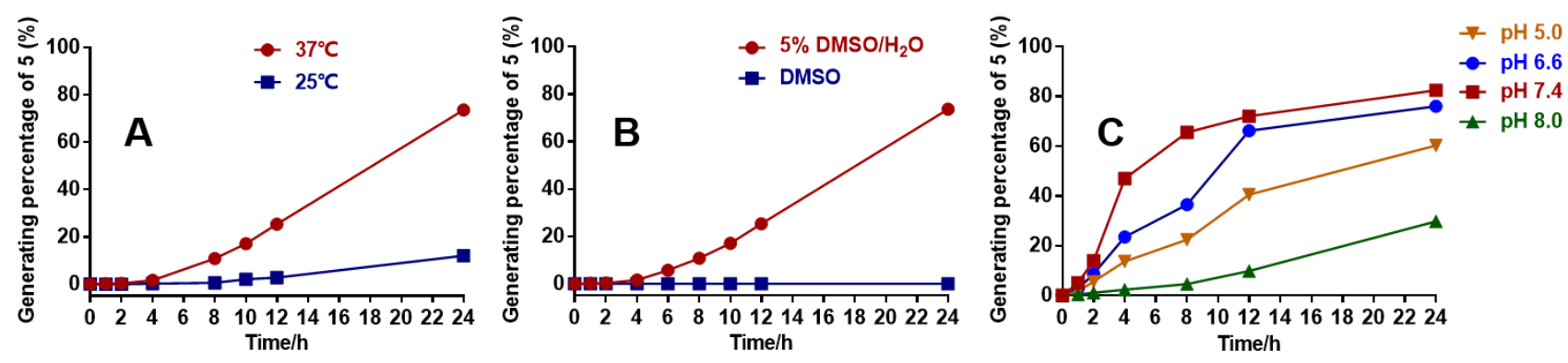

Figure S4. The effects of temperatures (A), water $(\mathbf{B})$ and $\mathrm{pH}$ values $(\mathbf{C})$ on the 1-triggered depropargylation. Solution of the 5a $(250 \mu \mathrm{M})$ and $\mathbf{1}(250 \mu \mathrm{M})$ in the indicated conditions, A) PBS (pH 7.4) containing 5\% DMSO, at $37{ }^{\circ} \mathrm{C}$ or $25{ }^{\circ} \mathrm{C}$; B) PBS (pH 7.4) containing 5\% DMSO or in absolute DMSO at $37{ }^{\circ} \mathrm{C}$; C) PBS containing 5\% DMSO PBS under the indicated $\mathrm{pH}$ values at $37{ }^{\circ} \mathrm{C}$, were 
incubated. Aliquots $(300 \mu \mathrm{L})$ from group $(\mathbf{A})$ and $(\mathbf{B})$ at each time point were subjected to 96 -well plates and measured the fluorscence intensity $\left(\lambda_{\text {ex/em }}=325 / 455 \mathrm{~nm}\right)$ to determine the concentrations of fluorescent compound $\mathbf{5}$ according to the previously established standard curve of concentrationsfluorenscence intensity, data were expressed as the mean \pm SD from three experiments. Aliquots $(600 \mu \mathrm{L})$ from group (C) at each time point were subjected to HPLC analysis to determine the concentrations of generating concentrations of 5 .

+TOF MS: 4.934 min from st.wiff Agilent

Max. 7.6 e5 counts.

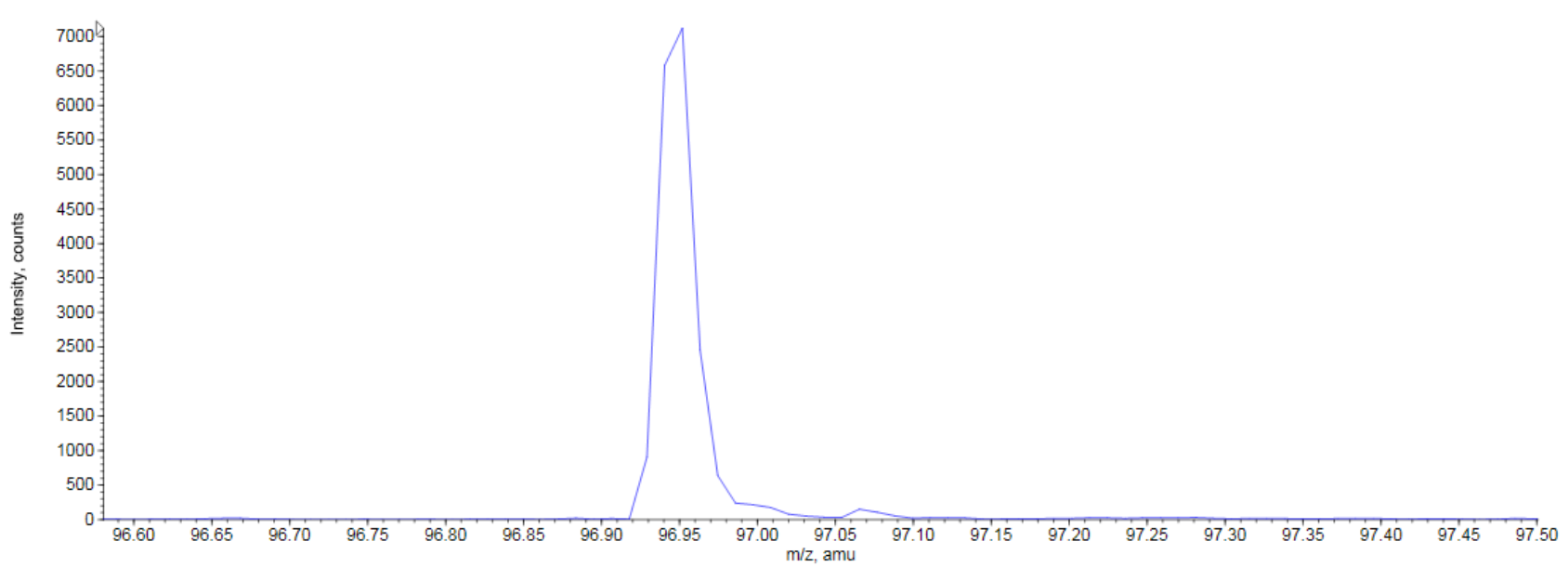

Figure S5. $1(500 \mu \mathrm{M})$ was incubated with compound 5a $(500 \mu \mathrm{M})$ in $\mathrm{PBS}(\mathrm{pH}=7.4)$ at $37{ }^{\circ} \mathrm{C}$ for $24 \mathrm{~h}$. Then, the reaction mixture was subjected to LC-MS for analysis. As shown above, the mass of hydroxyacetone in the reaction mixture was captured, m/z: $96.95[\mathrm{M}+\mathrm{Na}]^{+}$ 

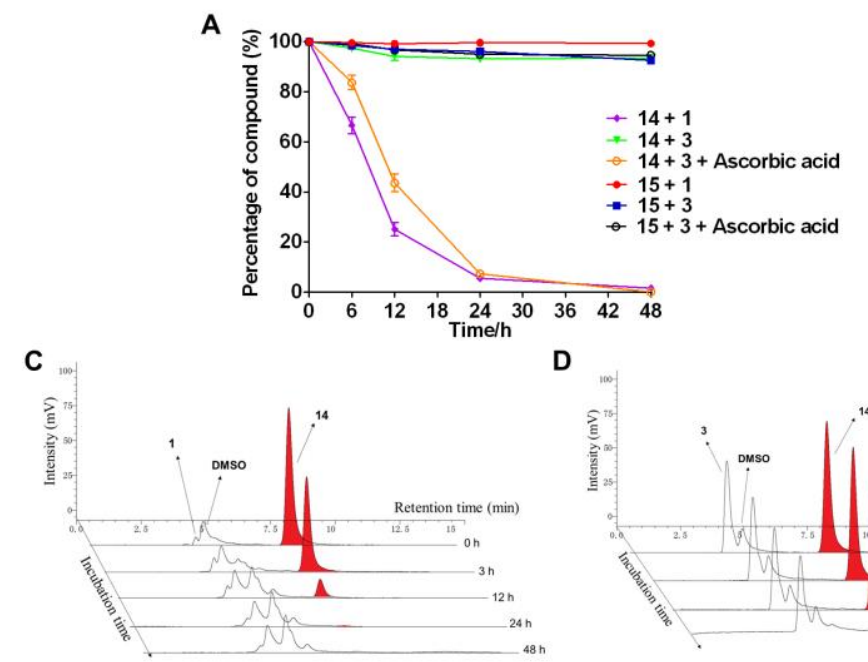

D

(1)

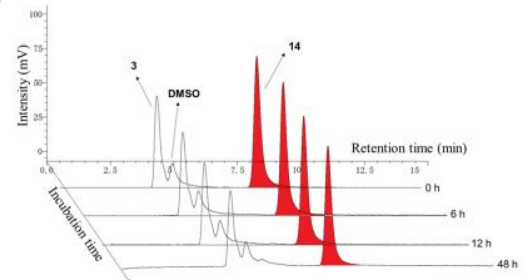

E

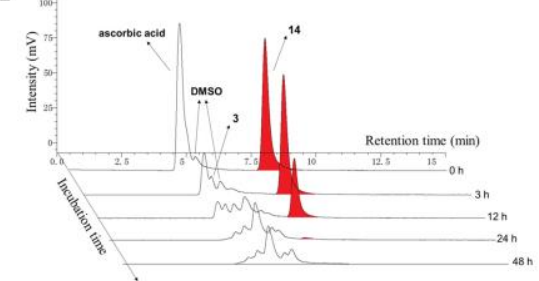

G

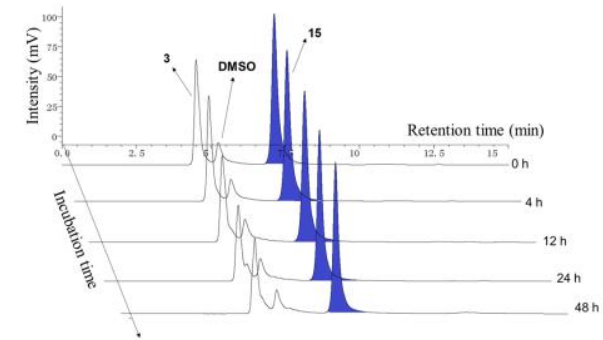

Figure S6. A) Decomposition kinetics of $14(125 \mu \mathrm{M})$ or $15(125 \mu \mathrm{M})$ in the presence of equivalent concentrations $(125 \mu \mathrm{M})$ of $\mathbf{1}, \mathbf{3}$ or $\mathbf{3}+$ ascorbic acid in $\mathrm{PBS}\left(\mathrm{pH}=7.4,37^{\circ} \mathrm{C}\right.$, containing $5 \%$ DMSO) measured by HPLC analysis. B) NO release from $14(125 \mu \mathrm{M})$ or $15(125 \mu \mathrm{M})$ in the presence of equal concentrations $(125 \mu \mathrm{M})$ of $\mathbf{1}, \mathbf{3}$, or $\mathbf{3}+$ ascorbic acid in $\mathrm{PBS}\left(\mathrm{pH}=7.4,37^{\circ} \mathrm{C}\right.$, containing $5 \%$ DMSO). Error bars represent \pm SD from three independent experiments. The degradation of $14(125 \mu \mathrm{M})$ in the presence of equivalent concentration of C) $\mathbf{1}(125 \mu \mathrm{M})$, D) $\mathbf{3}(125 \mu \mathrm{M})$, E) $\mathbf{3}(125 \mu \mathrm{M})+$ ascorbic acid $(125 \mu \mathrm{M})$ in PBS $\left(\mathrm{pH}=7.4,37^{\circ} \mathrm{C}\right.$, containing 5\% DMSO) measured by HPLC at $254 \mathrm{~nm}$. It was found that both $\mathbf{1}$ and $\mathbf{3}$ + ascorbic acid effectively triggered the degradation of $\mathbf{1 4}$, whereas $\mathbf{3}$ alone was not able to catalyze the degradation of $\mathbf{1 4}$. The degradation of $\mathbf{1 5}(125 \mu \mathrm{M})$ in the presence of equivalent concentration of F) $1(125 \mu \mathrm{M}), \mathbf{G}) \mathbf{3}(125 \mu \mathrm{M})$ in PBS $\left(\mathrm{pH}=7.4,37^{\circ} \mathrm{C}\right.$, containing $5 \%$ DMSO) measured by HPLC at $254 \mathrm{~nm}$. It was found that neither 1 nor $\mathbf{3}$ triggered the degradation of $\mathbf{1 5}$. 


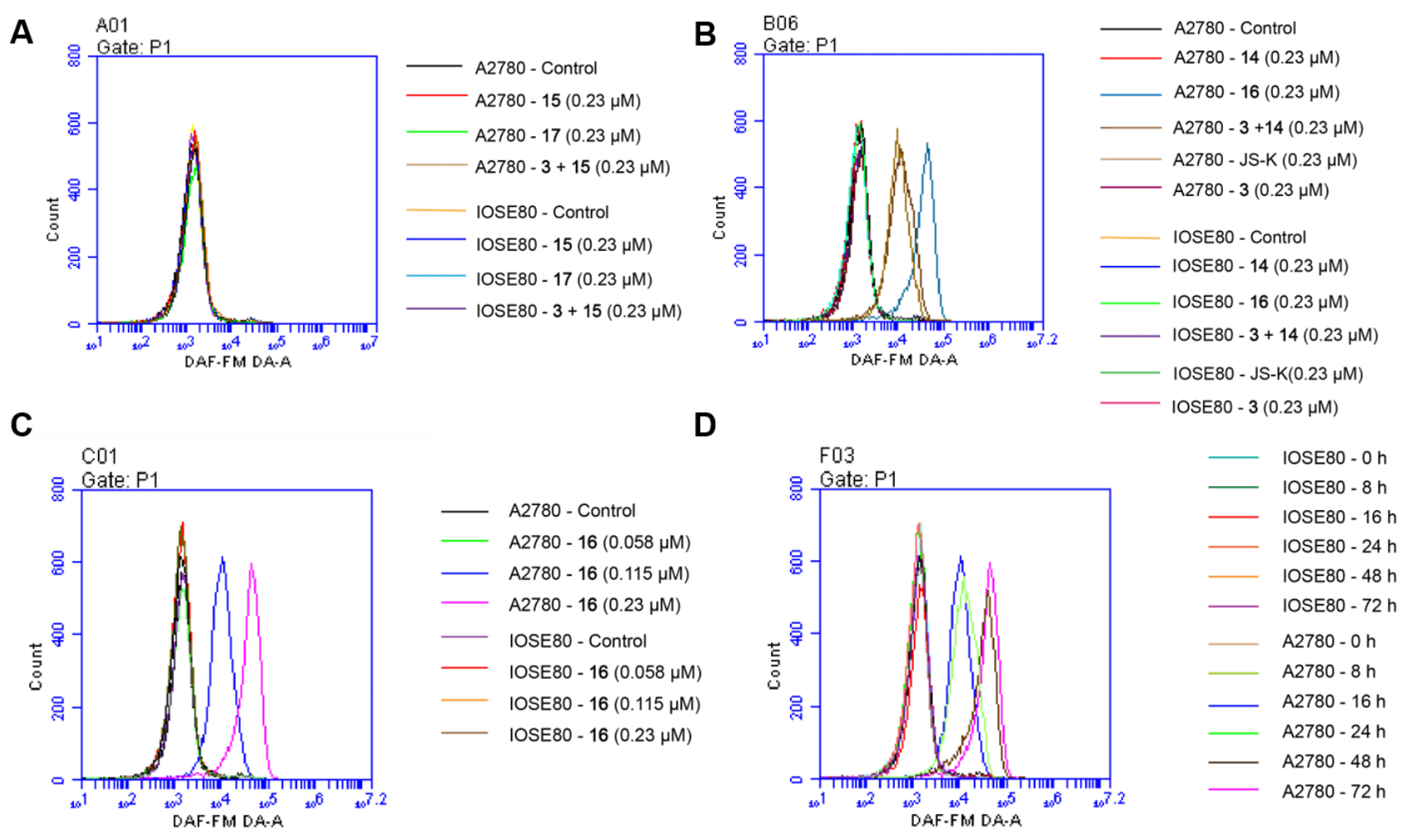

Figure S7. A) and B) NO released from the test compounds in A2780 and IOSE80 cells determined by an NO probe (DAF-FM DA). A2780 and IOSE80 cells were treated with or without $3(0.23 \mu \mathrm{M})$ for 10 $\mathrm{h}$, then the cells were rinsed with PBS three times, and resuspended with equivalent concentration $(0.23$ $\mu \mathrm{M})$ of the test compounds for $8 \mathrm{~h}$. The cells were then collected and resuspended with DAF-FM DA (5 $\mu \mathrm{M})$ for 20 mins in the dark, and then analysed by fluorescence-activated cell sorting (FACS). NO release from 16 in A2780 and IOSE80 cells determined by DAF-FM DA. C) The cells were treated with different concentrations of $\mathbf{1 6}(0.058,0.115,0.23 \mu \mathrm{M})$ for $8 \mathrm{~h}$. D) The cells treated with $\mathbf{1 6}(0.058 \mu \mathrm{M})$ for different times $(0,8,16,24,48,72 \mathrm{~h})$. The cells were then collected and resuspended with DAF-FM DA $(5 \mu \mathrm{M})$ for 20 mins in the dark, and then analyzed by fluorescence-activated cell sorting (FACS). 


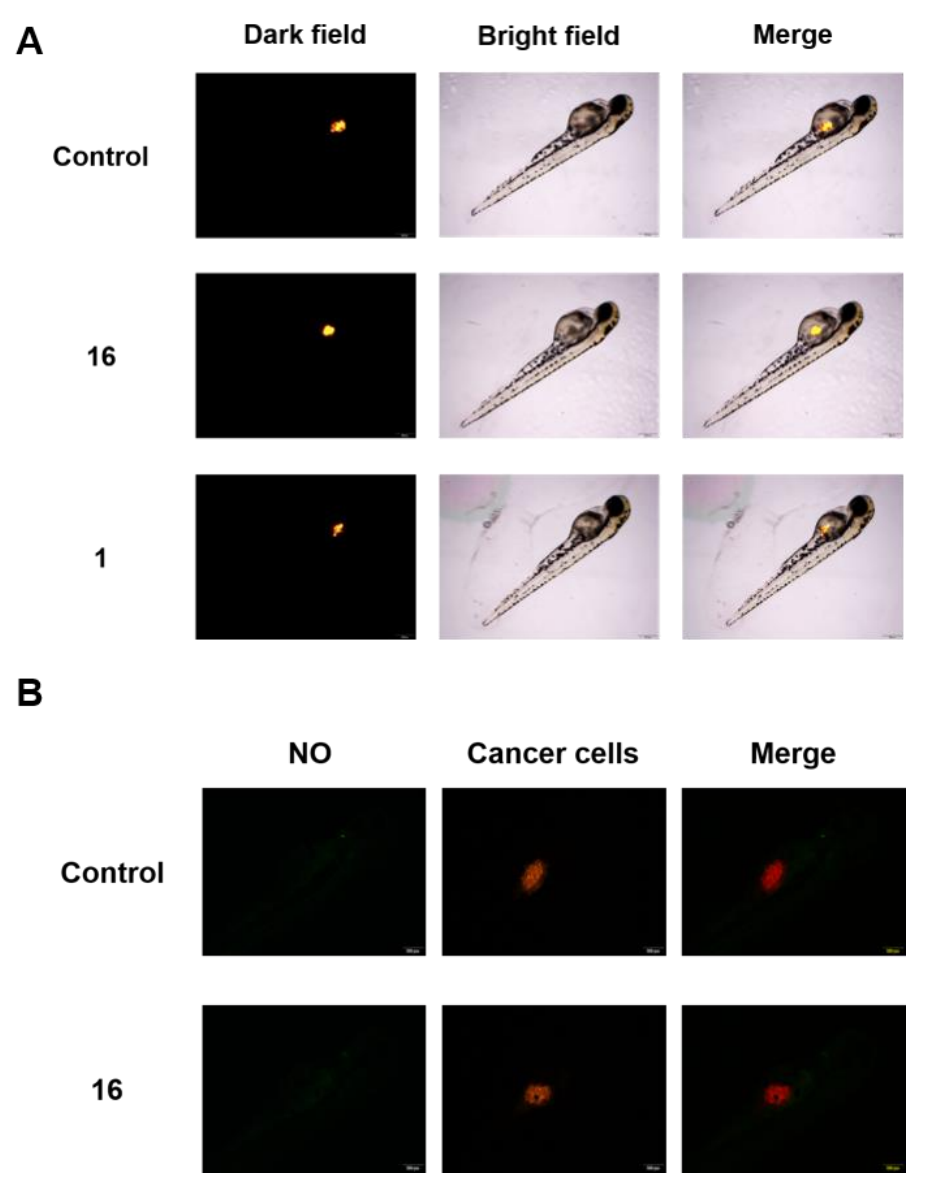

Figure S8. A) In the assay to evaluate the anticancer activity of $\mathbf{1 6}$ in zebrafish implanted with Dil-labeled A2780 cells (illustrated in Figure 6A), the representative confocal microscopy images of zebrafish for each group at $0 \mathrm{~h}$ before administration of the test compounds. B) In the dual-imaging assay (illustrated in Figure 6D), the representative confocal microscopy images of xenografts model zebrafish for each group at $0 \mathrm{~h}$ before administration of the test compounds. 
2. NMR, HRMS and HPLC Spectra for compounds 14-17.

$O^{2}$-propargyl 1-( $N$-methyl-2-(4-oxo-butanoic acid-4-yl)-oxy-ethylamine- $N$-yl)-diazen-1-ium-1,2-diolate (14)

PD $1 \mathrm{H}-\mathrm{NMR}$ CDCl3 303K AV-300

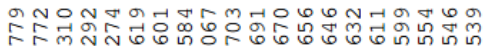

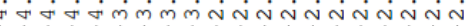

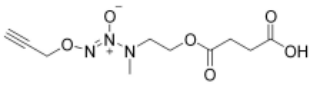

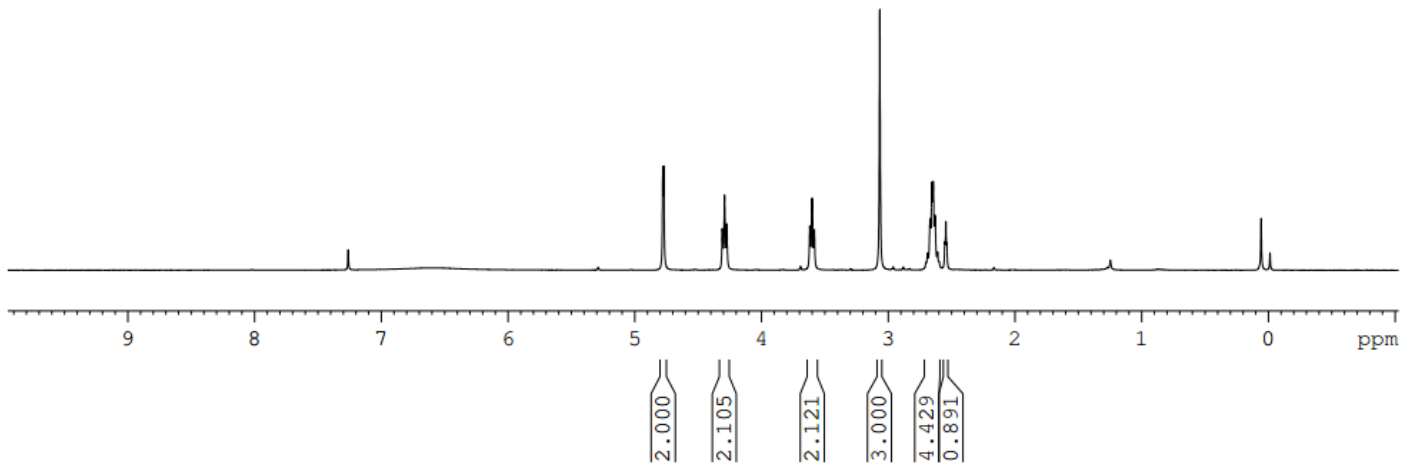

PD 13C-NMR CDCl3 303K AV-300

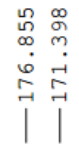
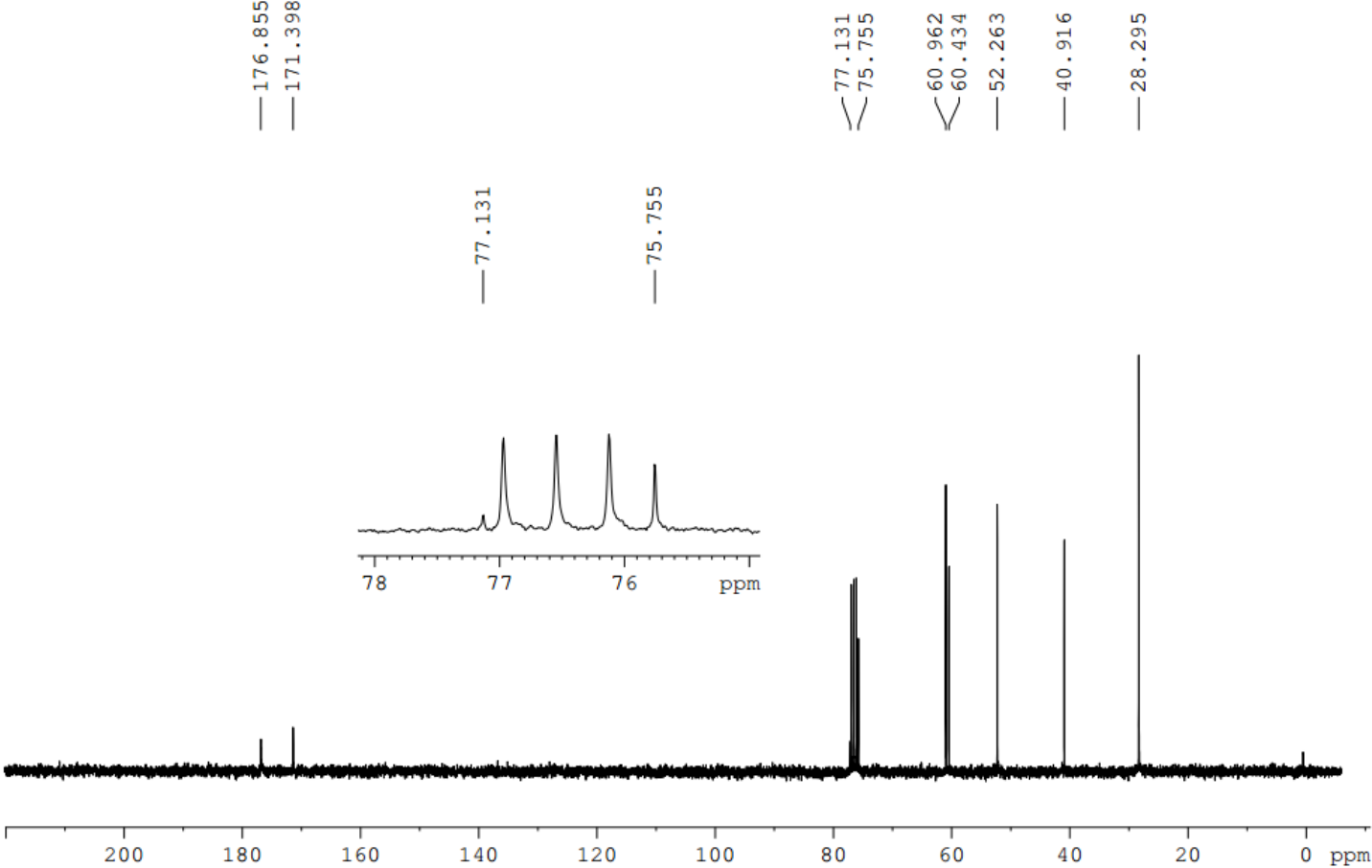


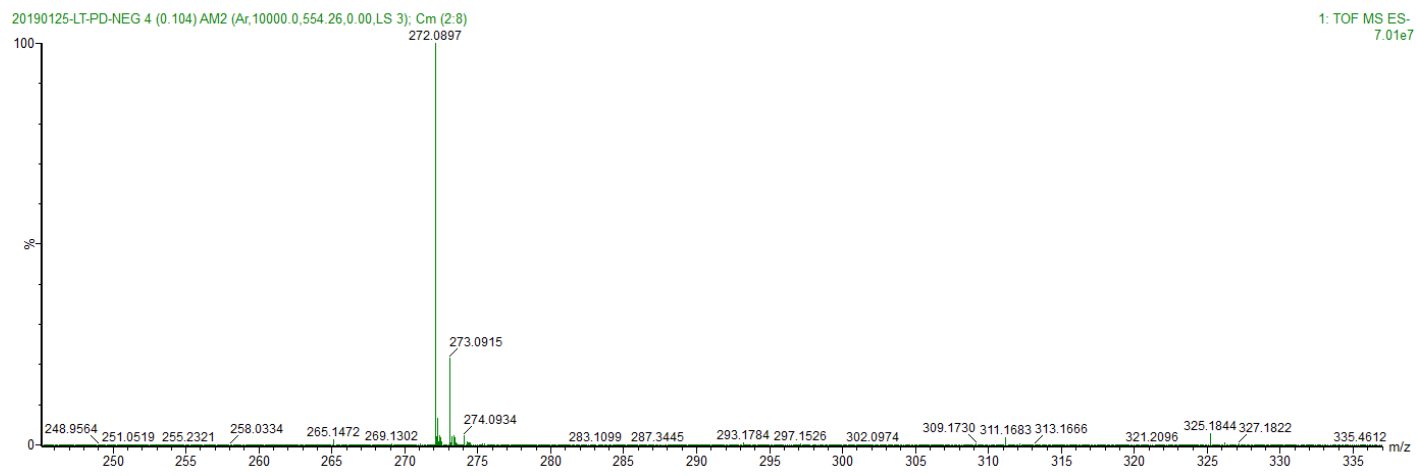

$O^{2}$-methyl 1-( $N$-methyl-2-(4-oxo-butanoic acid-4-yl)-oxy-ethylamine- $N$-yl)-diazen-1-ium-1,2-diolate (15)

MD $1 \mathrm{H}-\mathrm{NMR} \quad \mathrm{CDCL} 3 \quad 303 \quad \mathrm{AV}-500$

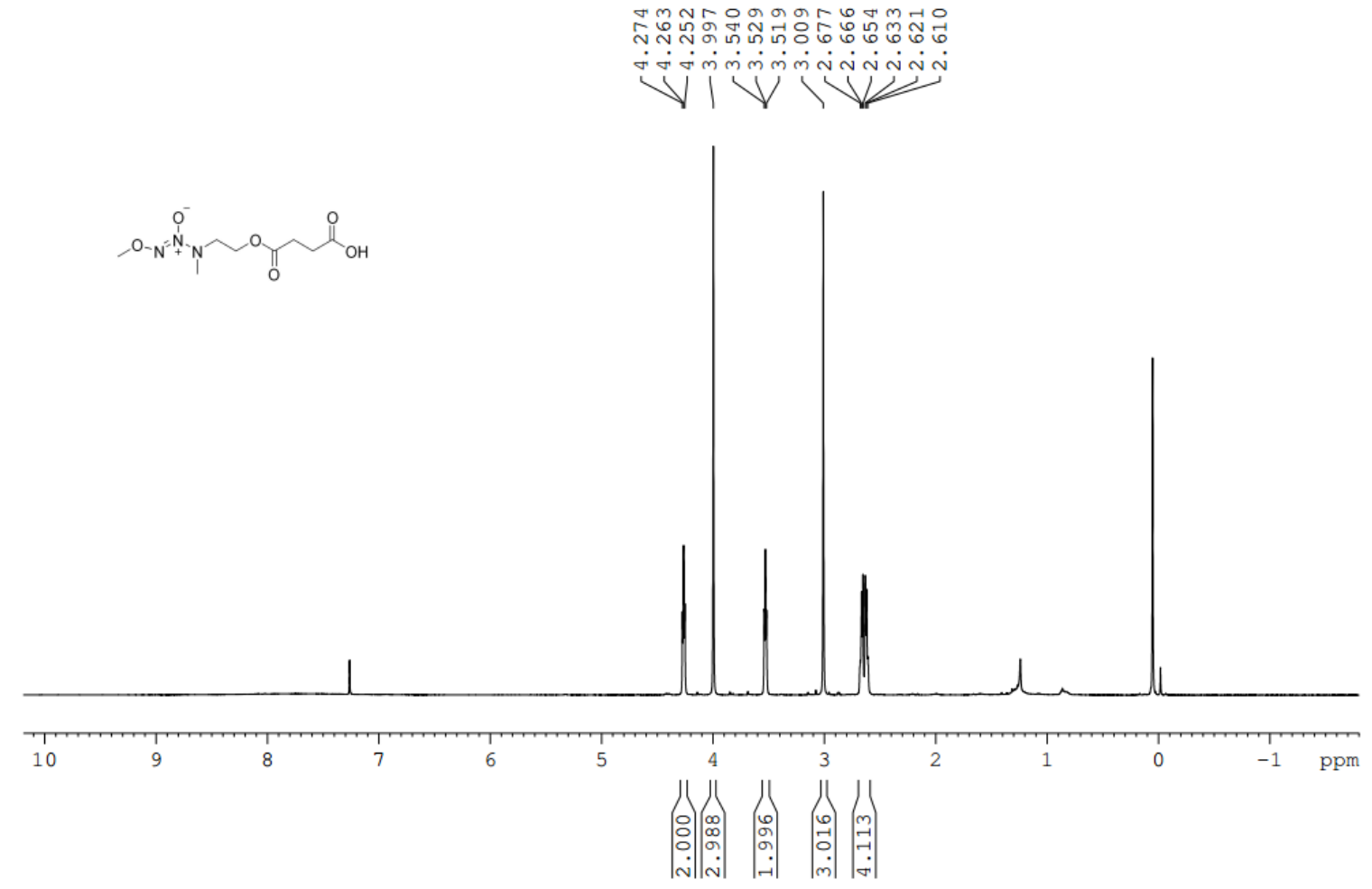


MD 13C-NMR CDCL3 $303 \quad \mathrm{AV}-500$

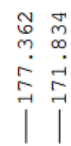

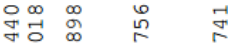

نं
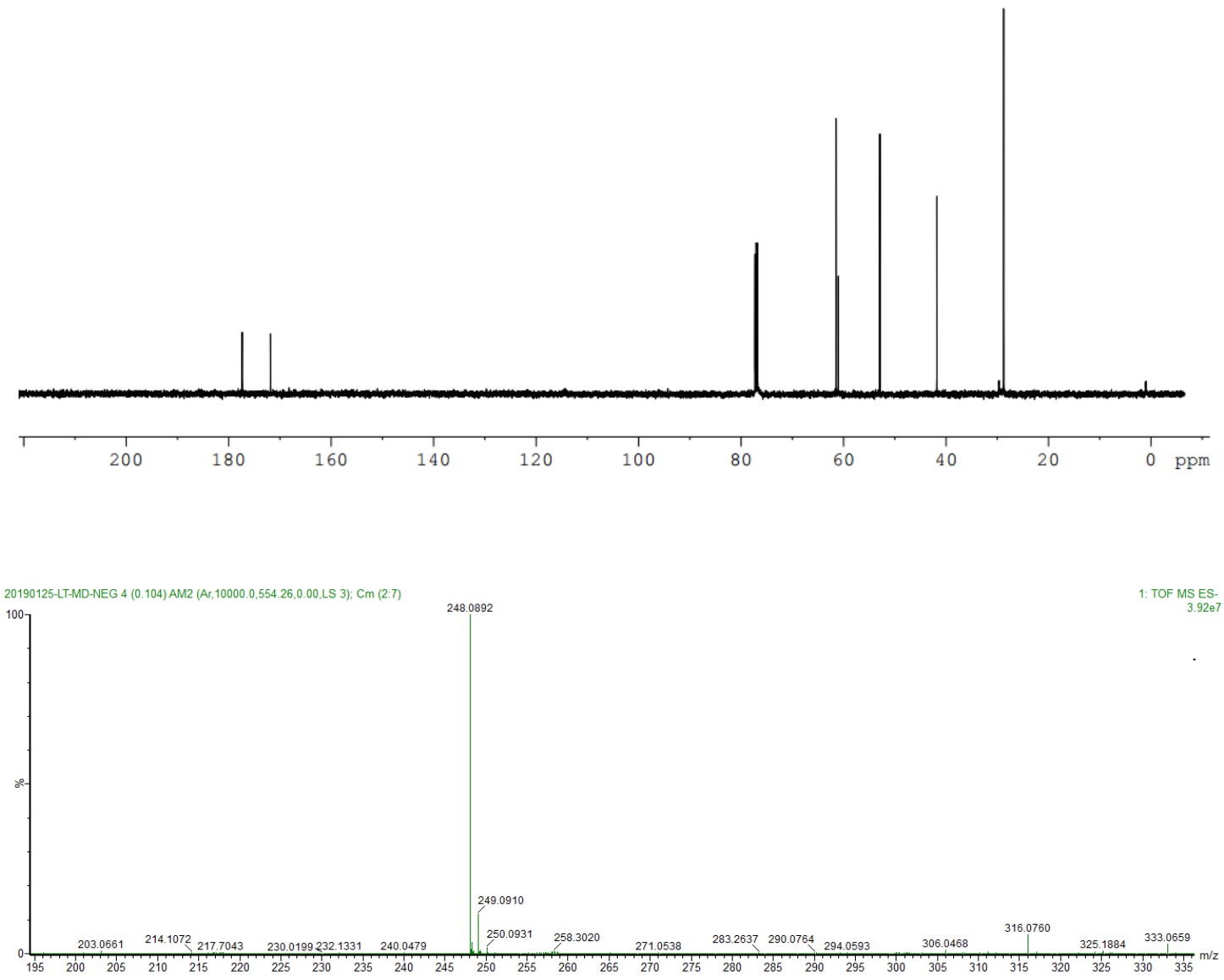
$\mathrm{O}^{2}$-propargyl 1-(N-methyl-2-(4-oxo-butanoic acid diamine trichloro hydroxyl platinum ester-4-yl)-oxyethylamine- $N$-yl)-diazen-1-ium-1,2-diolate (16)

PDP H1-NMR DMSO-d6 303K AV-300
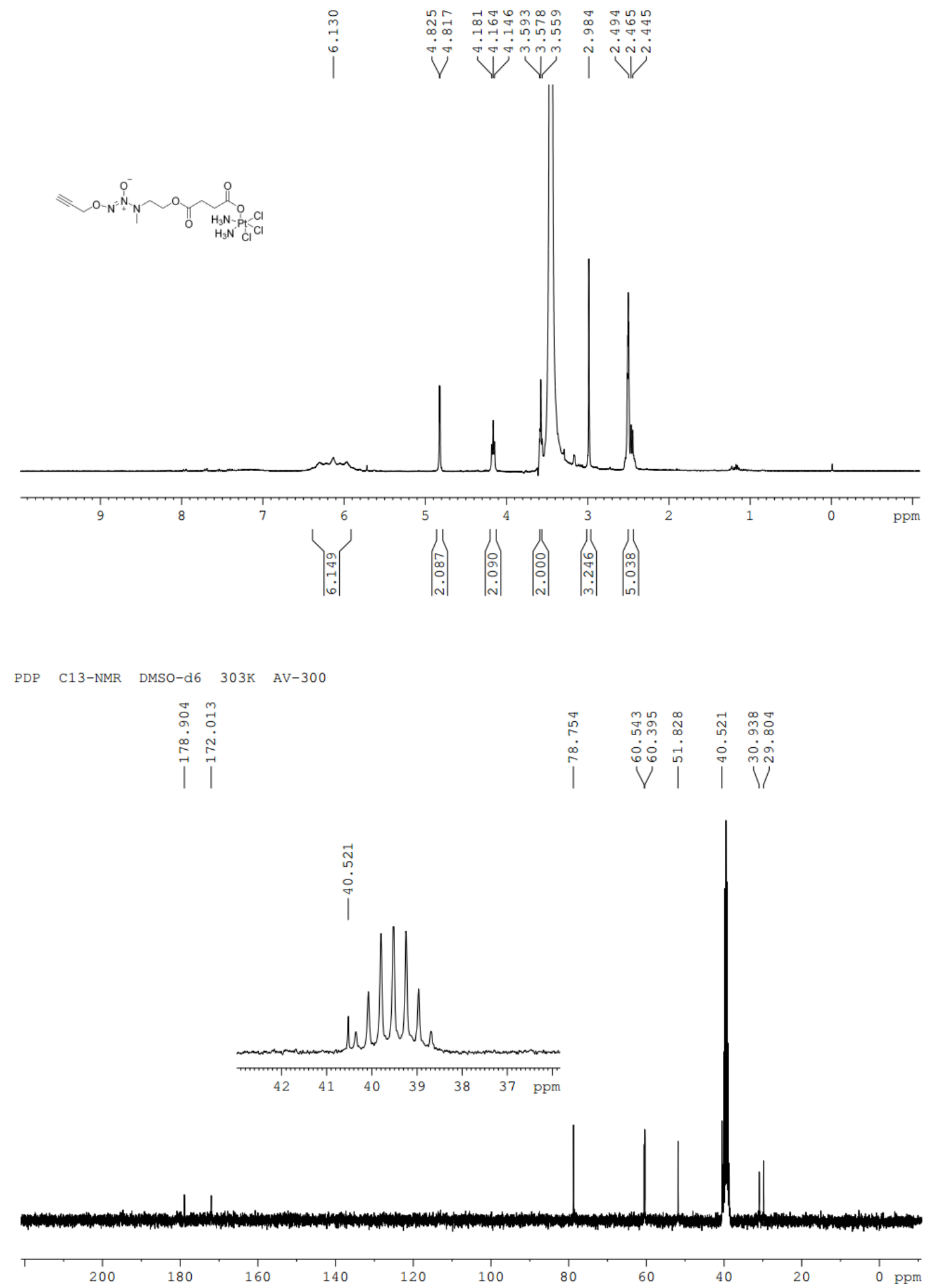


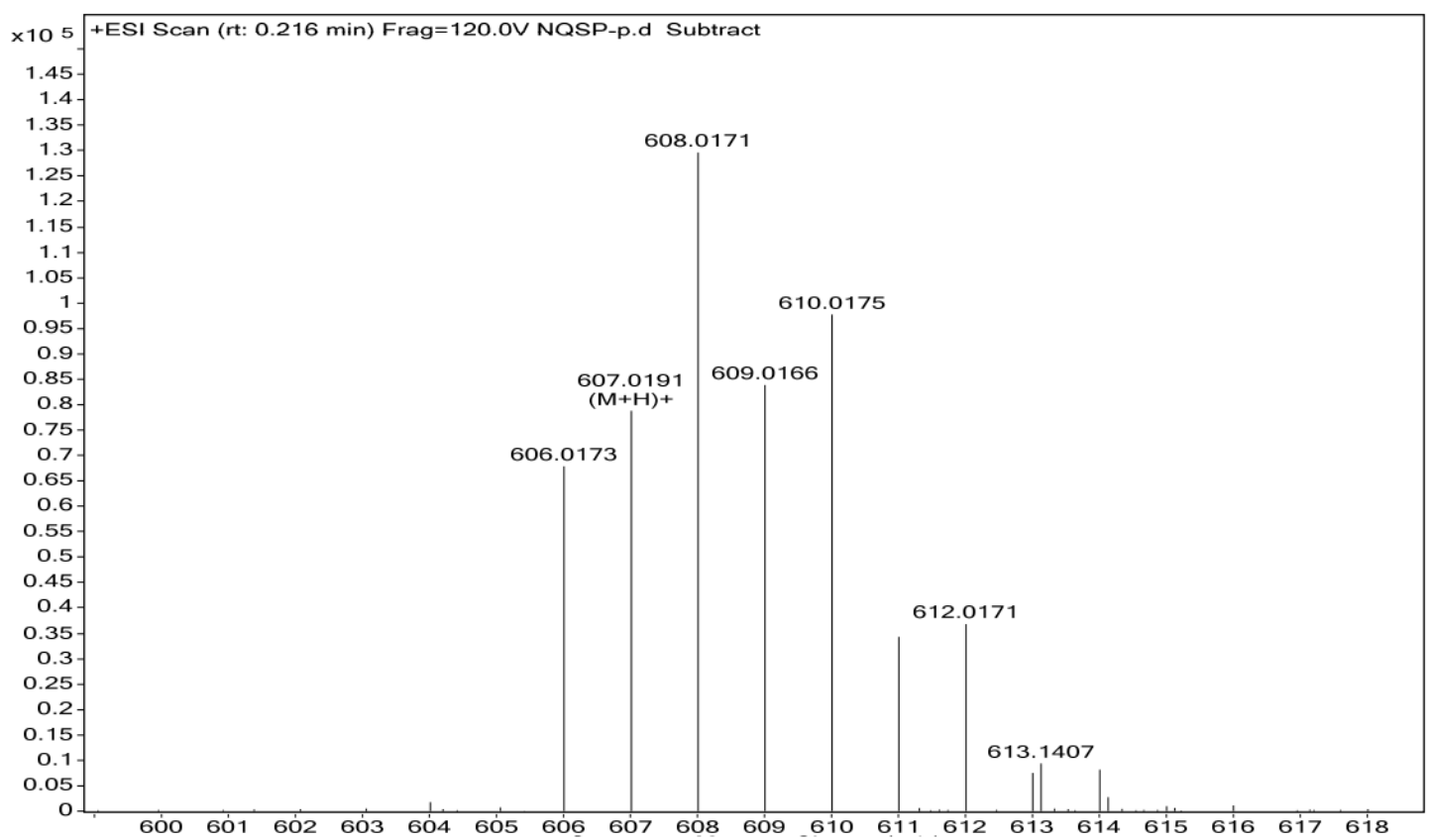

$\mathrm{O}^{2}$-methyl 1-(N-methyl-2-(4-oxo-butanoic acid diamine trichloro hydroxyl platinum ester-4-yl)-oxyethylamine- $N$-yl)-diazen-1-ium-1,2-diolate (17)

MDP $\quad 1 \mathrm{H}-\mathrm{NMR} \quad$ DMSO-D $6 \quad 303 \mathrm{~K} \quad$ AV-500

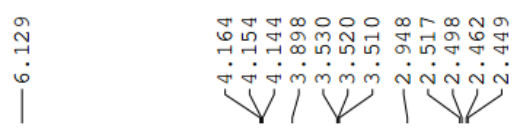

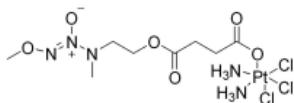

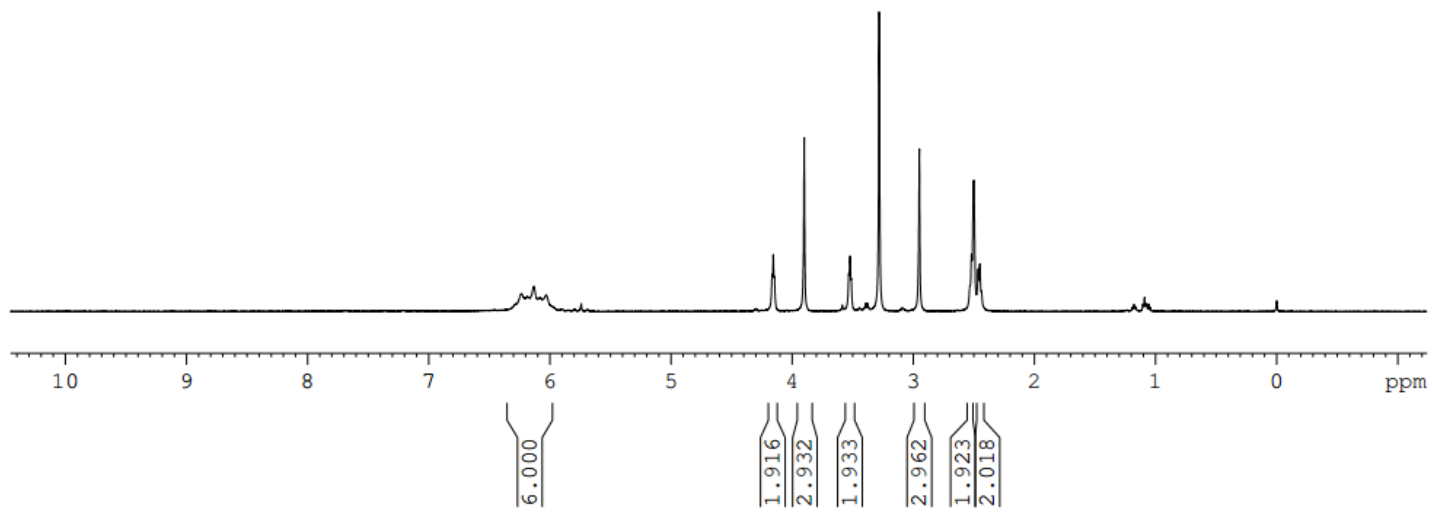


공
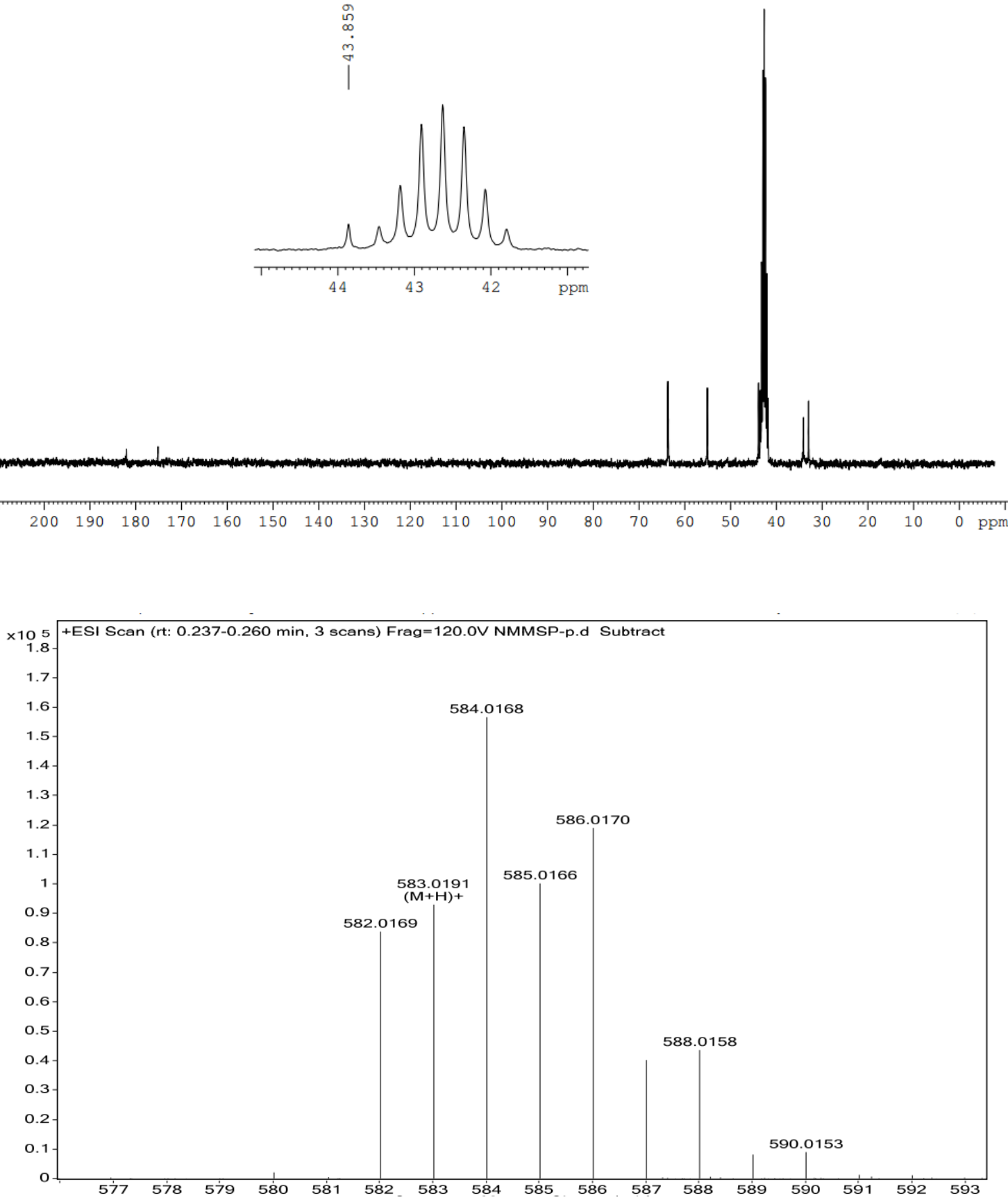
HPLC spectra of compound 14-17.

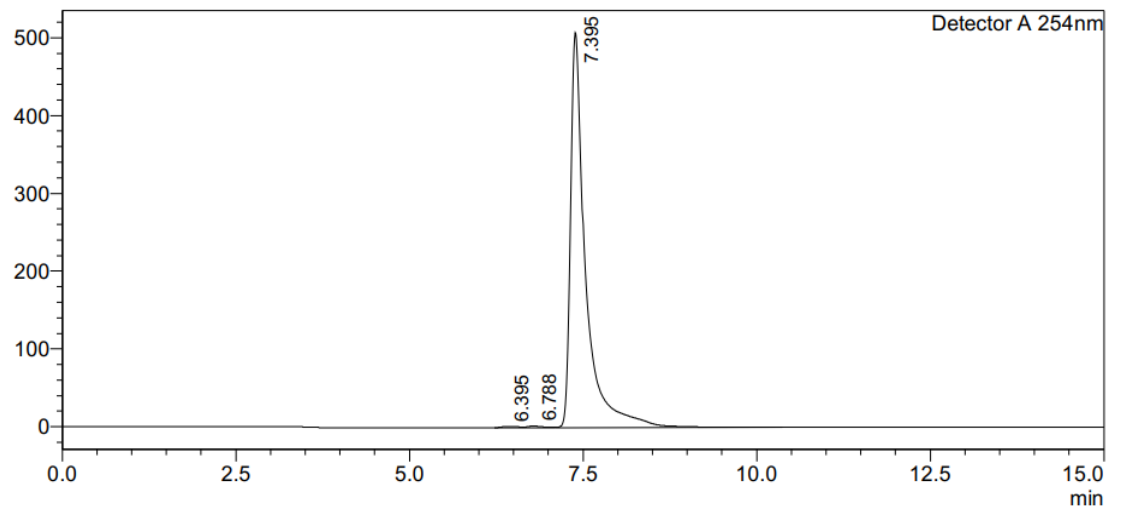

Compound 14. Column: Innovai ODS-2 $(250 \mathrm{~mm} \times 4.6 \mathrm{~mm} \times 5 \mu \mathrm{m}, 100 \AA \AA)$; Mobile phase: methanol/water $=60 / 40$; Rate: $0.50 \mathrm{~mL} / \mathrm{min}$; Detection wavelength: $254 \mathrm{~nm}$; Temperature: $25^{\circ} \mathrm{C}$; Purity $99.32 \%$.

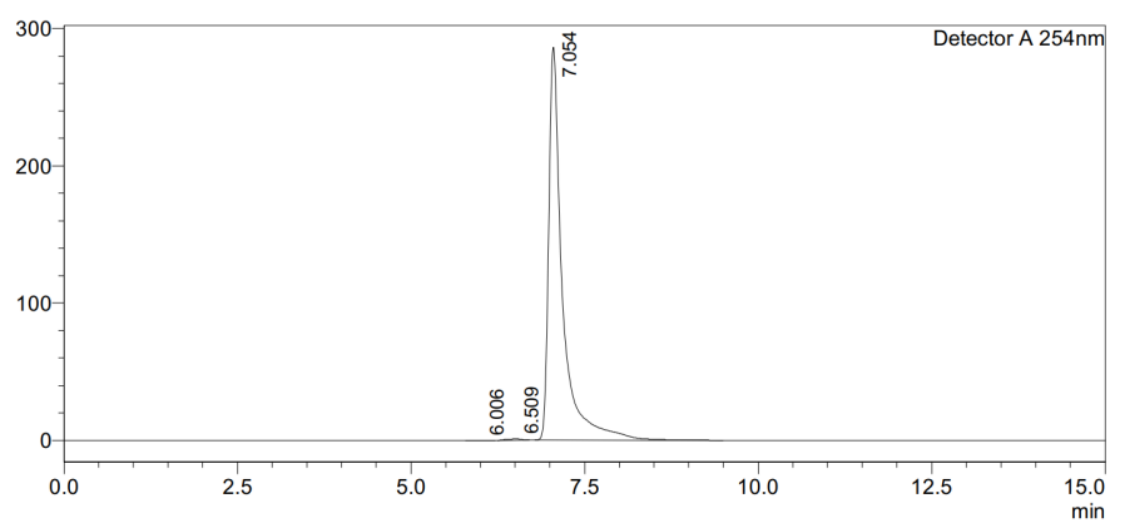

Compound 15. Column: Innovai ODS-2 $(250 \mathrm{~mm} \times 4.6 \mathrm{~mm} \times 5 \mu \mathrm{m}, 100 \AA)$; Mobile phase: methanol/water $=60 / 40$; Rate: $0.50 \mathrm{~mL} / \mathrm{min}$; Detection wavelength: $254 \mathrm{~nm}$; Temperature: $25^{\circ} \mathrm{C}$; Purity $99.65 \%$.

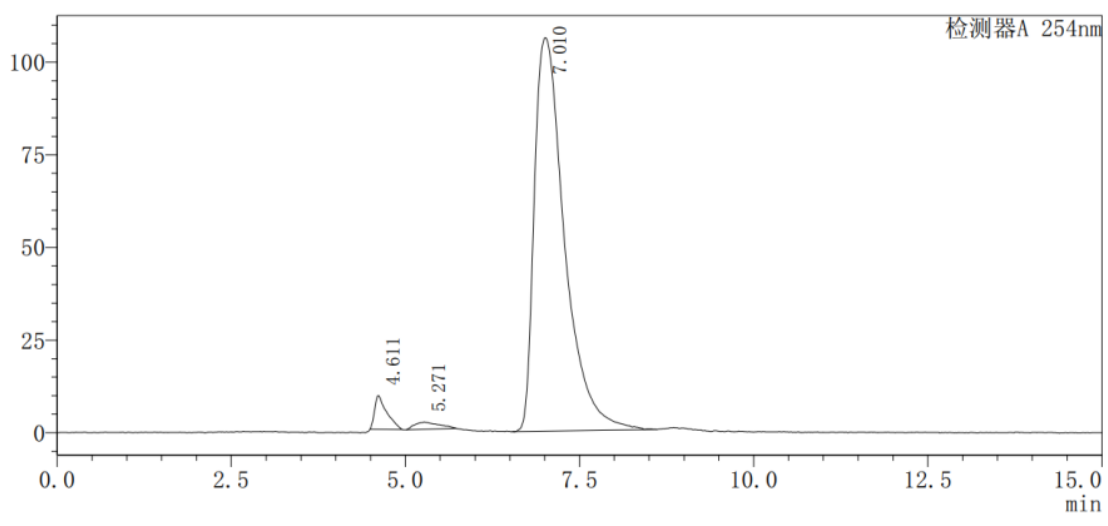

Compound 16. Column: Innovai ODS-2 $(250 \mathrm{~mm} \times 4.6 \mathrm{~mm} \times 5 \mu \mathrm{m}, 100 \AA)$; Mobile phase: methanol/water $=60 / 40$; Rate: $0.65 \mathrm{~mL} / \mathrm{min}$; Detection wavelength: $254 \mathrm{~nm}$; Temperature: $25^{\circ} \mathrm{C}$; Purity $95.39 \%$. 


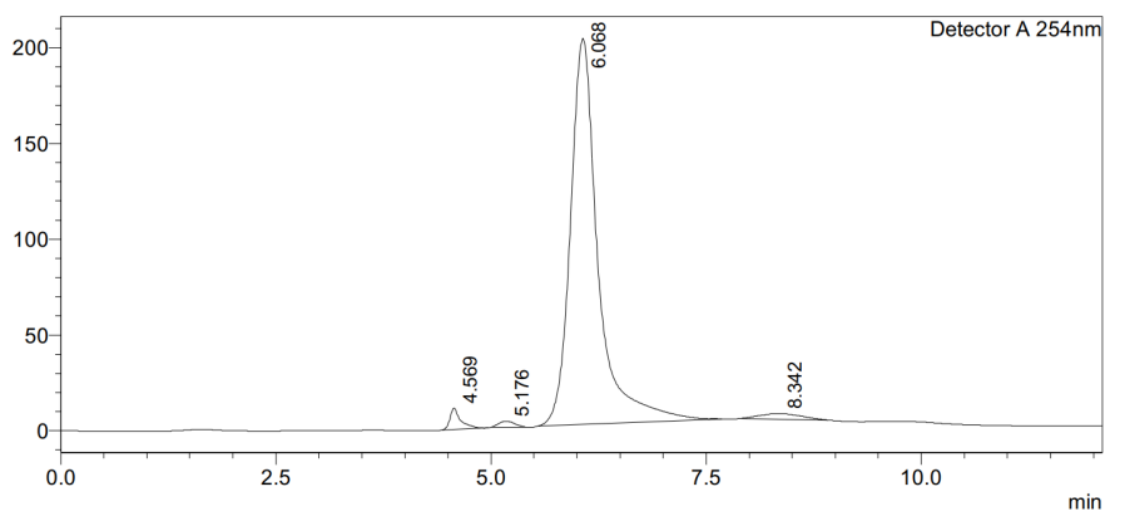

Compound 17. Column: Innovai ODS-2 $(250 \mathrm{~mm} \times 4.6 \mathrm{~mm} \times 5 \mu \mathrm{m}, 100 \AA \AA)$; Mobile phase: methanol/water $=60 / 40$; Rate: $0.65 \mathrm{~mL} / \mathrm{min}$; Detection wavelength: $254 \mathrm{~nm}$; Temperature: $25^{\circ} \mathrm{C}$; Purity $95.16 \%$. 